\title{
Miscibility of Poly(Vinyl Chloride) with Poly(Ethylene Oxide) of Different Molecular Weights
}

\author{
M. Jakić, a," N. Stipanelov Vrandečić, ${ }^{a}$ V. Ocelić Bulatović, ${ }^{b}$ and E. Govorčin Bajsićb \\ aDepartment of Organic Technology, Faculty of Chemistry and Technology, \\ University of Split, Teslina 10/V, HR-21000 Split, Croatia \\ doi: 10.15255/CABEQ.2015.2290 \\ ${ }^{b}$ Department of Polymer Engineering and Organic Chemical Technology, \\ Faculty of Chemical Engineering and Technology, University of Zagreb, \\ Savska cesta 16/II, HR-10000 Zagreb \\ Original scientific paper \\ Received: August 20, 2015 \\ Accepted: March 16, 2016
}

In this work, five different techniques: dilute solution viscometry, differential scanning calorimetry (DSC), dynamic mechanical analysis (DMA), Fourier transform infrared spectroscopy (FT-IR), and scanning electronic microscopy (SEM) were employed in order to evaluate interactions of amorphous poly(vinyl chloride) (PVC) and semi-crystalline poly(ethylene oxide) (PEO) in solution and solid state. The results varied significantly from one experimental technique to another. The positive interactions between the investigated polymers were found over the whole composition range only in solution. However, in the solid state, by DSC and DMA analysis, the positive interactions were found only at elevated PVC content, while FT-IR and SEM analysis could not confirm interactions between the investigated polymers.

Key words:

miscibility, poly(ethylene oxide), poly(vinyl chloride)

\section{Introduction}

Poly(ethylene oxide) (PEO) is a semi-crystalline, biocompatible, biodegradable, non-ionic and water-soluble polymer of considerable industrial significance, which finds applications in many different branches of industry. ${ }^{1}$ It is commercially available in a wide range of molecular weights (20 $000-8000000)$. In the blend with poly(vinyl chloride) (PVC), it can be used as a thermal energy storage material, and as a host polymer electrolyte in solid state batteries. ${ }^{2-6}$ PEO is an organic component in organic-anorganic hybrid material applied in advanced technologies in the field of functional coatings with superior barrier properties. These barrier properties can be used to prevent migration of plasticizers from PVC blood bags. The existence of ether bonds in PEO may result in the formation of a complex with PVC, which improves its adhesion on PVC substrate. ${ }^{3}$ Likewise, there has been considerable interest in using PEO as membrane material for $\mathrm{CO}_{2}$ capture. ${ }^{7}$ However, due to weak mechanical property, neat PEO cannot be used at high temperatures and pressures. Ramesh et al. ${ }^{8}$ have demonstrated that the addition of PVC into PEO membranes improves their mechanical property. Generally, by mixing two or more different polymers together, it is possible to achieve the various

${ }^{*}$ Corresponding author: e-mail: mjakic@ktf-split.hr (Miće Jakić) properties of the final material. Recently, the problem of polymer blends has also become important regarding recycling and waste disposal. Hence, the better understanding of the interactions between these two polymers is very important.

Theoretically, miscibility of PVC and PEO could be expected based on the fact that the $\mathrm{O}$ atoms of PEO can form hydrogen bonds (H-bonds) with the $\mathrm{H}$ atoms in the $\mathrm{CHCl}$ groups of PVC. Furthermore, the electron-rich $\mathrm{O}$ atom in PEO may act as donor and have an attractive interaction with the electron-deficient $\mathrm{Cl}$ atom in PVC. ${ }^{7}$ Miscibility, mechanical, optical, morphological, and thermal properties of PVC/PEO blends have already been studied in the literature. ${ }^{2-4,7-24}$ However, data on the miscibility of PVC and PEO are contradictory. Margaritis and Kalfoglou ${ }^{10}$ found that PVC and PEO were miscible for PVC-rich blends according to results obtained by dynamic mechanical analysis, differential scanning calorimetry, and optical microscopy. Similarly, Marco et al. ${ }^{11}$ by ${ }^{13} \mathrm{C}$ NMR study concluded that the $\mathrm{PEO} / \mathrm{PVC}$ blend was thermodynamically stable at PVC content $>40 \%$. Vice versa, Castro et al. ${ }^{18}$ pointed out that PVC/PEO blends were miscible at PVC content $<60 \%$. On the other hand, by inverse gas chromatography (IGC) Etxeberria et al. ${ }^{12}$ observed that the blends were more miscible at high PVC content ( $80 \mathrm{wt} \% \mathrm{PVC}$ ) or PEO content ( $80 \mathrm{wt} \%$ PEO), while the two polymers were less compatible at $\mathrm{PVC} / \mathrm{PEO}$ composi- 
tion of 50/50. Luo and Jiang ${ }^{7}$ came to similar conclusions according to results obtained by atomistic molecular dynamic and mesoscale dissipative dynamics (DPD) simulations. The morphologies obtained by DPD simulations demonstrated that the $\mathrm{PVC} / \mathrm{PEO}$ blend of 50/50 composition is less miscible than 70/30 and 30/70 blends. Neiro et al. ${ }^{4}$ investigated the miscibility of PVC with PEO by viscosimetric, microscopic and thermal analyses, and showed that miscibility was dependent on the molecular weight of PVC, thus when low molecular weight PVC is used, miscibility could be expected. The miscibility of the PVC/PEO blend was explained as a result of donor-acceptor interactions between the chlorine atoms of PVC, as a weak acceptor species, and oxygen atoms of the PEO, as a donor species. Kaczmarek et al. ${ }^{19}$ had a similar conclusion with the exception that interactions are possible because PEO is a proton-accepting agent (due to the ether atom in each unit) and PVC is a proton-donating polymer (because of $\alpha$-hydrogen atoms). On the other hand, by differential scanning calorimetry and viscosimetric analyses, Ramesh et $a l .{ }^{2}$ showed that the PVC/PEO blends are fully miscible. The latter author confirmed his own conclusions in the melt and solution by differential scanning calorimetry and X-ray diffraction (XRD) analysis, respectively. ${ }^{21}$ Since the ionic conductivity occurs in the amorphous part of the polymer, the influence of the amorphous PVC on the crystallization of semi-crystalline PEO was investigated as well. ${ }^{13}$

In most of the above-mentioned experimental studies, low molecular weight PEO is used (2 200 -200000 ) or molecular weight is not indicated. In addition, conclusions on the miscibility of PVC and PEO were made on the basis of PEO melting point depression by DSC. Unfortunately, there is no information about the influence of the amorphous PVC on the PEO glass transition temperature, or about the influence of the semi-crystalline PEO on the PVC glass transition temperature. The problem lies in the fact that the PVC glass transition phenomenon is overlapped with the PEO melting process, and those two effects cannot be separated by using conventional DSC.

The properties of the blends strongly depend on the methods and conditions of the preparation, components' miscibility, entanglement and crystallinity, specific interactions, sample morphology, as well as the molecular weight and its distribution. In this work, five different techniques: dilute solution viscometry, DSC, DMA, FT-IR, and SEM were used. Dilute solution viscometry has the advantage of not being affected by the crystallinity or morphological states of polymers in the blend. This technique determines miscibility according to the fact that molecules of both polymers may exist in a molecularly dispersed state in solution and undergo a mutual attraction or repulsion, which will influence the viscosity. The attractions between polymers may cause swelling of macromolecular coils leading to an increase in viscosity, while repulsion may cause shrinkage of the macromolecular coils, leading to a decrease in viscosity. The objective of this work was to investigate the use of viscosimetry to evaluate the miscibility of a semi-crystalline PEO and amorphous $\mathrm{PVC}$ in solution, and to correlate the miscibility in the molten and solid states. PVC/PEO blends were usually prepared by solution casting. $2,4,8,11,13,14,18,19,21$ Because the polymer miscibility is often due to strong intermolecular interactions like hydrogen bonding, studies of miscibility carried out in solution may produce a system, which would be much closer to equilibrium in comparison to the system obtained by other techniques, e.g. extrusion. Hence, in this work, the samples were prepared by extrusion, a technique commonly used in the plastic industry, for DSC, DMA, FT-IR, and SEM analysis, in order to determine the interactions of polymers in the melt and solid state, respectively.

\section{Experimental}

\section{Materials}

Two different powders of PEO, supplied by Sigma-Aldrich, having the following average viscosimetric molecular weight, $\bar{M}_{\mathbf{v}} 100000$ (PEO1) and 300000 (PEO3) were utilized. The PVC powder used in this work had $\bar{M}_{\mathbf{v}} 86000$ and was supplied by Solvin. The PVC/PEOs blends of different mass fractions of polymers $(100 / 0,80 / 20,60 / 40,50 / 50$, 40/60, 20/80 and 0/100) for DSC, DMA, FT-IR, and SEM measurements were prepared by mixing the polymer powders followed by extrusion in a laboratory extruder (Dynisco, Qualitest North America) at $160{ }^{\circ} \mathrm{C}$ and screw speed $180 \mathrm{rpm}$. The samples were hot-pressed after extrusion at $120{ }^{\circ} \mathrm{C}$ for $30 \mathrm{~s}$. To prevent thermal degradation of PVC during the preparation of the blends, $2 \mathrm{wt} \%$ of $\mathrm{Ca} / \mathrm{Zn}$ stabilizer (Bärostab CT 9074x, Bärlocher, Italy) was added.

\section{Dilute solution viscometry}

The viscosity of PVC/PEOs blend solutions was measured by using the Ubbelohde capillary viscometer immersed in a constant temperature bath at $30.0 \pm 0.1^{\circ} \mathrm{C}$. A stock solution of each homopolymer was made by dissolving the polymer powder in distilled tetrahydrofurane (THF) up to a concentration of $0.5 \mathrm{~g} \mathrm{dL}^{-1}$. Binary solutions for each blend were prepared by mixing the appropriate quantity of filtered polymer solutions in the volume ratios of $80 / 20,60 / 40,50 / 50,40 / 60$ and $20 / 80$. The 
solutions of lower concentrations were made by adding the appropriate aliquots of solvent to the stock solution. Relative viscosities, $\eta_{\text {rel }}$, of polymer solutions were calculated by dividing the flow time of solutions, $t$, by the flow time of the pure solvent, $t_{0},\left(\eta_{\text {rel }}=\eta / \eta_{0}=t / t_{0}\right)$.

\section{Differential scanning calorimetry (DSC)}

The thermal characteristics of PVC/PEO blends were investigated by means of differential scanning calorimetry (Mettler Toledo DSC $823^{\mathrm{e}}$ ) in a nitrogen atmosphere $\left(50 \mathrm{~cm}^{3} \mathrm{~min}^{-1}\right)$. Calibration was performed with metallic indium, and the samples were pressed in aluminium pans. Samples of approximately $20 \mathrm{mg}$ were heated at a rate of $20{ }^{\circ} \mathrm{C} \mathrm{min}-1$ from -90 to $120{ }^{\circ} \mathrm{C}$, cooled at the same rate to $-90{ }^{\circ} \mathrm{C}$, and reheated to $120{ }^{\circ} \mathrm{C}$. The samples were kept at -90 and $120{ }^{\circ} \mathrm{C}$ for $10 \mathrm{~min}$. The $T_{\mathrm{g}}$ was determined from the second heating cycle according to international standard ISO $11357-2^{25}$ as the extrapolated onset temperature ( $\left.T_{\text {eig }}\right)$, as midpoint temperature $\left(T_{\mathrm{mg}}\right)$, and as the extrapolated end temperature $\left(T_{\text {efg }}\right)$. The corresponding change of the specific heat capacity $\left(\Delta c_{\mathrm{p}}\right)$ was determined as well. The melting point of samples of approximately $10 \mathrm{mg}$ was determined from DSC curves obtained at the heating rate of $10{ }^{\circ} \mathrm{C} \mathrm{min}{ }^{-1}$ from 25 to $120^{\circ} \mathrm{C}$ according to international standard ISO $11357-3^{26}$, as the extrapolated onset temperature $\left(T_{\text {eim }}\right)$, as peak temperature $\left(T_{\mathrm{pm}}\right)$, and as the extrapolated end temperature $\left(T_{\text {efim }}\right)$. The crystallization temperatures were determined in the same way as the $T_{\text {eic }}, T_{\text {pc }}$, and $T_{\text {efm }}$ from DSC cooling curves performed at the cooling rate of $10{ }^{\circ} \mathrm{C} \mathrm{min}^{-1}$ from 120 to $25{ }^{\circ} \mathrm{C}$ according to the latter international standard. The enthalpy of melting and crystallization, $\Delta H_{\mathrm{m}}$ and $\Delta H_{\mathrm{c}}$, were determined as the area of endothermic and exothermic peak, respectively. The degree of crystallinity was calculated from the following equation:

$$
\mathrm{X}_{c}(\%)=\frac{\Delta H_{m}}{\Delta H^{0} \cdot w} \cdot 100
$$

where $\Delta H_{\mathrm{m}}$ and $\Delta H^{0}$ are apparent melting enthalpies per gram of PEOs present in the blend and of neat PEO, respectively, while $w$ represents the weight percentage of PEOs in the blend. The melting enthalpy per gram of neat PEO $\left(\Delta H^{0}\right)$ is $188.1 \mathrm{~J} \mathrm{~g}^{-1} .^{27}$

\section{Dynamic mechanical analysis (DMA)}

Dynamic mechanical analysis measurements were carried out on a DMA 983 Dynamic Mechanical Analyzer (TA Instruments, USA). The samples were cooled to $-100{ }^{\circ} \mathrm{C}$ and then heated to $120{ }^{\circ} \mathrm{C}$ at a frequency of $1 \mathrm{~Hz}$ with a constant heating rate of $2{ }^{\circ} \mathrm{C} \mathrm{min}^{-1}$. The sample length between the clamps was approximately $25 \mathrm{~mm}$. All the samples were cooled to $-100^{\circ} \mathrm{C}$ using liquid nitrogen.

\section{Fourier transform infrared spectroscopy (FT-IR)}

FT-IR spectra were recorded on Perkin Elmer Spectrum One FT-IR spectrometer by the Horizontal Attenuated Total Reflectance (HATR) technique. The internal reflection crystal, made of zinc selenide ( $\mathrm{ZnSe}$ ), had a $45^{\circ}$ angle of incidence to the IR beam. The spectra were acquired in the measurement range of $4000-650 \mathrm{~cm}^{-1}$ at room temperature. Signals were collected in 10 scans at a resolution of $4 \mathrm{~cm}^{-1}$ and rationed against a background spectrum recorded from the empty $\mathrm{ZnSe}$ crystal at room temperature.

\section{Scanning electron microscopy (SEM)}

The surface morphological analysis of the samples was carried out using scanning electron microscope (Joel JSM-6510LV, Japan). The samples were coated with gold (Bio Rad-SEM Coating System) and examined under high vacuum at $15 \mathrm{kV}$.

\section{Results and discussion}

\section{Dilute solution viscometry}

The application of the dilute solution viscometry method for the study of interactions and miscibility in dilute multicomponent polymer solutions has been described in several papers. ${ }^{28-32}$ From the efflux time of each polymer blend, measured by the serial dilution technique, the specific viscosity, $\eta_{\text {sp }}=\eta_{\text {rel }}-1$, was calculated for different concentrations. The intrinsic viscosity, $[\eta]$, was determined by plotting reduced viscosity, $\eta_{\mathrm{sp}} / c$, against the solution concentration, $c$, according to the Huggins extrapolation equation (2):

$$
\frac{\eta_{\mathrm{sp}}}{c}=[\eta]+K_{\mathrm{H}}[\eta]^{2} c
$$

where $K_{\mathrm{H}}$ is the Huggins constant. Linear relationships were observed for the pure polymers and for all of the PVC/PEOs blends over the whole composition range. From the slopes $b=K_{\mathrm{H}}[\eta]^{2}$ of these extrapolated straight lines, $K_{\mathrm{H}}$ constants can be obtained for each investigated blend. To evaluate interactions in the polymer blend from viscometric data, the parameter $\alpha$ has been used as proposed by Sun et al. ${ }^{28}$

$$
\alpha=K_{\text {blend }}-K_{1}
$$

where $K_{\text {blend }}$ is the experimental Huggins constant obtained from equation (2), and $K_{1}$ is a parameter for the blend calculated from the viscometric data of each pure polymer solution, considering the composition of the blend, according to the equation (4): 


$$
\begin{gathered}
K_{1}=\frac{K_{\mathrm{A}}[\eta]_{\mathrm{A}}^{2} w_{\mathrm{A}}^{2}+K_{\mathrm{B}}[\eta]_{\mathrm{B}}^{2} w_{\mathrm{B}}^{2}}{\left(K_{\mathrm{A}}[\eta]_{\mathrm{A}}+K_{\mathrm{B}}[\eta]_{\mathrm{B}}\right)^{2}}+ \\
+\frac{2 \sqrt{K_{\mathrm{A}} K_{\mathrm{B}}}[\eta]_{\mathrm{A}} w_{\mathrm{A}}[\eta]_{\mathrm{B}} w_{\mathrm{B}}}{\left(K_{\mathrm{A}}[\eta]_{\mathrm{A}}+K_{\mathrm{B}}[\eta]_{\mathrm{B}}\right)^{2}}
\end{gathered}
$$

where $K_{\mathrm{A}},[\eta]_{\mathrm{A}}, w_{\mathrm{A}}$ and $K_{\mathrm{B}},[\eta]_{\mathrm{B}}, w_{\mathrm{B}}$ are Huggins constant, intrinsic viscosity, and mass fraction of PVC and PEOs, respectively. Viscometry data, i.e. intrinsic viscosity, $[\eta]$, experimental Huggins constant, $K_{\mathrm{H}}$, parameter $K_{1}$ and interaction parameter $\alpha$ are shown in Table 1 . If $\alpha>0$, attractive forces between polymers occur and miscibility is found. If $\alpha<0$, repulsive forces will prevail and miscibility should not be expected. Positive values of $\alpha$ were found for all investigated PVC/PEOs blends as shown in Fig. 1. Parameter $\alpha$ is about ten times smaller for PVC blends with PEO of higher molecular weight. Thus, when low molecular weight PEO1 is used, miscibility could be expected. These results are in accordance with those of Neiro et al. ${ }^{4}$

\begin{tabular}{|c|c|c|c|c|c|c|c|c|}
\hline Blend & Parameter & $100 / 0$ & $80 / 20$ & $60 / 40$ & $50 / 50$ & $40 / 60$ & $20 / 80$ & $0 / 100$ \\
\hline \multirow{4}{*}{$\begin{array}{l}\mathrm{PVC} / \\
\mathrm{PEO} 1\end{array}$} & {$[\eta] / \mathrm{cm}^{3} \mathrm{~g}^{-1}$} & 78 & 79 & 77 & 77 & 76 & 87 & 84 \\
\hline & $K_{\mathrm{H}}$ & 0.318 & 0.642 & 0.728 & 0.770 & 0.760 & 0.632 & 0.373 \\
\hline & $K_{1}$ & - & 0.329 & 0.341 & 0.346 & 0.352 & 0.363 & - \\
\hline & $\alpha$ & - & 0.313 & 0.387 & 0.424 & 0.408 & 0.269 & - \\
\hline \multirow{4}{*}{$\begin{array}{l}\mathrm{PVC} / \\
\mathrm{PEO} 3\end{array}$} & {$[\eta] / \mathrm{cm}^{3} \mathrm{~g}^{-1}$} & 78 & 125 & 155 & 175 & 184 & 229 & 270 \\
\hline & $K_{\mathrm{H}}$ & 0.318 & 0.381 & 0.405 & 0.413 & 0.421 & 0.428 & 0.416 \\
\hline & $K_{1}$ & - & 0.362 & 0.385 & 0.39 & 0.39 & 0.409 & - \\
\hline & $\alpha$ & - & 0.019 & 0.020 & 0.020 & 0.022 & 0.019 & - \\
\hline
\end{tabular}

Table 1 - Viscometric data for PVC/PEO blends

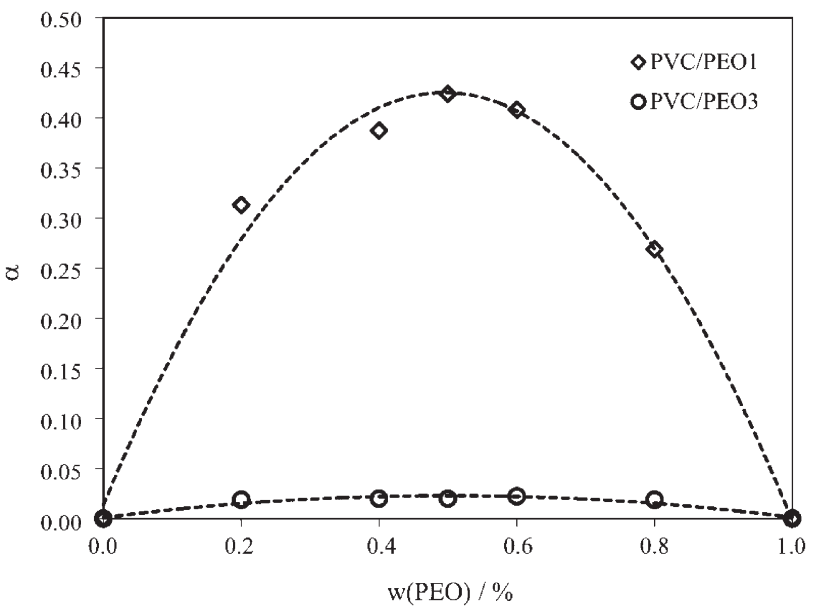

Fig. 1 - Relationships between $\alpha$ and $w(P E O)$ for all investigated PVC/PEOs blends

\section{Differential scanning calorimetry}

The results of the DSC measurements are shown in Fig. 2 as normalized DSC curves of neat polymers and PVC/PEO1 blends. Thermal transition parameters of all investigated PVC/PEOs blends are shown in Tables 2 and 3. The DSC curve of neat PVC (Fig. 2(b)) shows one glass transition temperature at $78{ }^{\circ} \mathrm{C}\left(T_{\text {eig }}\right), 82{ }^{\circ} \mathrm{C}\left(T_{\text {mg }}\right)$, and $86{ }^{\circ} \mathrm{C}$ $\left(T_{\text {efg }}\right)$, which is the characteristic temperature of an amorphous polymer. The corresponding change of the specific heat capacity $(\Delta c)$ of neat PVC is $0.34 \mathrm{~J} \mathrm{~g} \mathrm{~g}^{-1}{ }^{\circ} \mathrm{C}^{-1}$. On the other hand, the DSC heating curve of neat PEO1 (Fig. 2(b)) shows one glass transition at $-56{ }^{\circ} \mathrm{C}\left(T_{\text {eig }}\right),-51{ }^{\circ} \mathrm{C}\left(T_{\text {mg }}\right)$, and $-45^{\circ} \mathrm{C}$

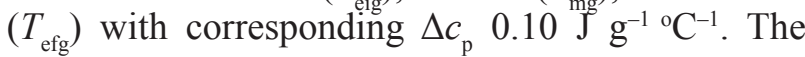
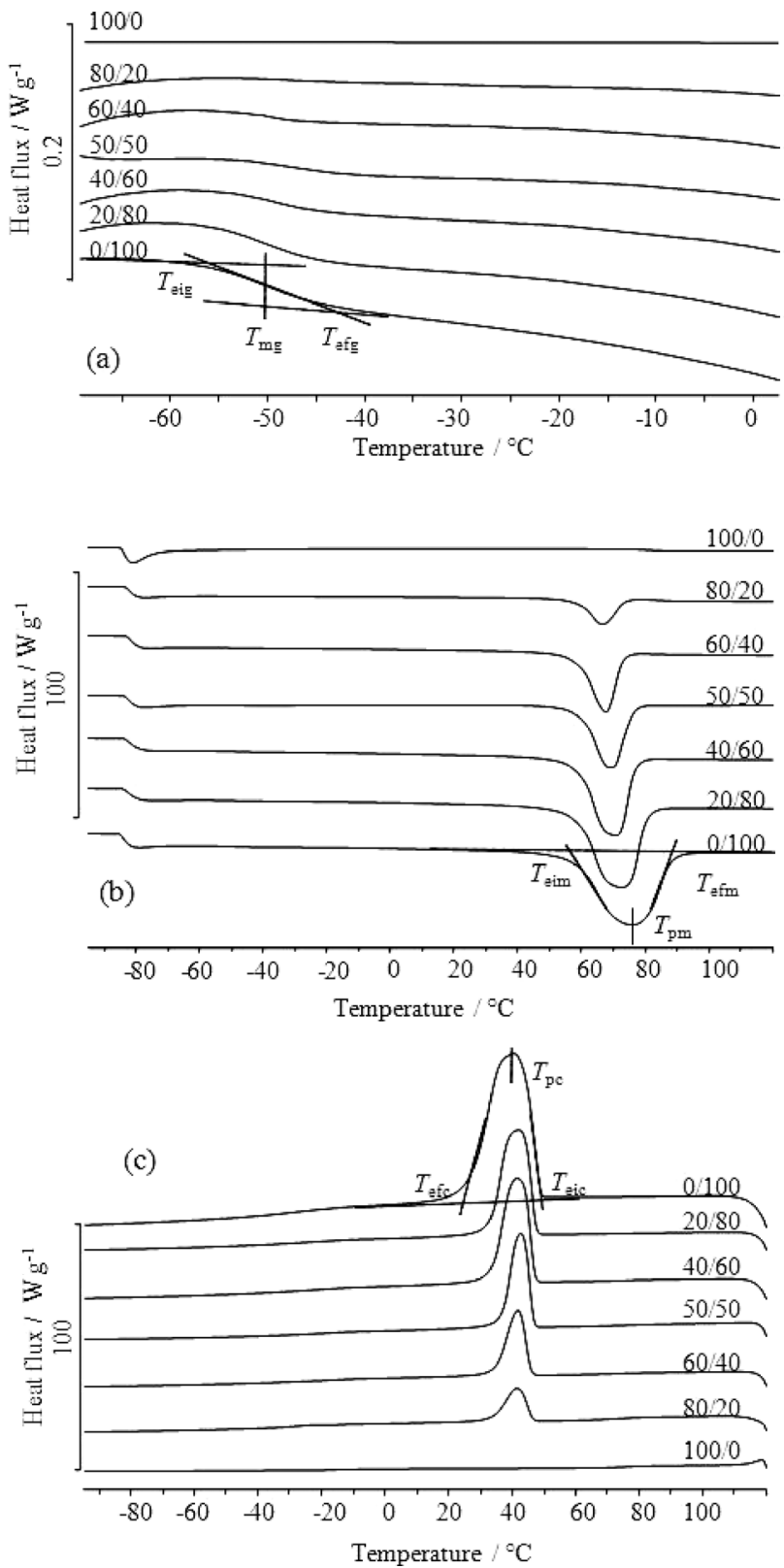

Fig. 2 - Normalized DSC curves of PVC/PEO1 blends: (a) glass transition, (b) melting and (c) crystallization 
Table 2 - Thermal transition parameters of the PVC/PEO1 blends for DSC measurements

\begin{tabular}{|c|c|c|c|c|c|c|c|}
\hline \multirow{2}{*}{ Parameter } & \multicolumn{7}{|c|}{ PVC/PEO1 } \\
\hline & $100 / 0$ & $80 / 20$ & $60 / 40$ & $50 / 50$ & $40 / 60$ & $20 / 80$ & $0 / 100$ \\
\hline$T_{\text {eig }}$ & 78 & -53 & -56 & -54 & -55 & -54 & -56 \\
\hline$T_{\mathrm{g}}{ }^{\circ} \mathrm{C}$ & 82 & -48 & -52 & -49 & -50 & -50 & -51 \\
\hline$T_{\text {efg }}$ & 86 & -40 & -45 & -44 & -45 & -45 & -45 \\
\hline$\Delta c_{\mathrm{p}} / \mathrm{J} \mathrm{g}^{-1}{ }^{\circ} \mathrm{C}^{-1}$ & 0.34 & 0.03 & 0.04 & 0.03 & 0.07 & 0.08 & 0.10 \\
\hline \multirow[b]{2}{*}{$T_{\mathrm{m}} /{ }^{\circ} \mathrm{C}$} & - & 60 & 61 & 60 & 61 & 60 & 61 \\
\hline & - & 65 & 66 & 65 & 65 & 65 & 72 \\
\hline$T_{\text {efm }}$ & - & 69 & 70 & 72 & 71 & 73 & 79 \\
\hline$\Delta H_{\mathrm{m}} / \mathrm{J} \mathrm{g}^{-1}$ & - & 27.8 & 64.9 & 80.0 & 98.3 & 135.1 & 159.6 \\
\hline$T_{\text {eic }}$ & - & 49 & 49 & 49 & 49 & 49 & 51 \\
\hline$T_{\mathrm{c}} /{ }^{\circ} \mathrm{C} \quad T_{\mathrm{pc}}$ & - & 46 & 46 & 46 & 46 & 47 & 47 \\
\hline$T_{\text {efc }}$ & - & 41 & 41 & 41 & 40 & 38 & 35 \\
\hline$-\Delta H_{\mathrm{c}} / \mathrm{J} \mathrm{g}^{-1}$ & - & 24.6 & 56.5 & 71.5 & 89.1 & 122.0 & 145.8 \\
\hline$X_{\mathrm{c}} / \%$ & - & 74 & 86 & 85 & 87 & 90 & 85 \\
\hline
\end{tabular}

Table 3 - Thermal transition parameters of the PVC/PEO3 blends for DSC measurements

\begin{tabular}{|c|c|c|c|c|c|c|c|}
\hline \multirow{2}{*}{ Parameter } & \multicolumn{7}{|c|}{$\mathrm{PVC} / \mathrm{PEO} 3$} \\
\hline & $100 / 0$ & $80 / 20$ & $60 / 40$ & $50 / 50$ & $40 / 60$ & $20 / 80$ & $0 / 100$ \\
\hline$T_{\text {eig }}$ & 78 & -51 & -55 & -55 & -55 & -54 & -56 \\
\hline$T_{\mathrm{g}} /{ }^{\circ} \mathrm{C} \quad T_{\mathrm{mg}}$ & 82 & -45 & -50 & -51 & -51 & -50 & -51 \\
\hline$T_{\text {efg }}$ & 86 & -40 & -44 & -45 & -45 & -45 & -46 \\
\hline$\Delta c_{\mathrm{p}} / \mathrm{J} \mathrm{g}^{-1}{ }^{\circ} \mathrm{C}^{-1}$ & 0.34 & 0.03 & 0.06 & 0.06 & 0.07 & 0.09 & 0.14 \\
\hline$T_{\text {eim }}$ & - & 60 & 60 & 60 & 60 & 61 & 63 \\
\hline$T_{\mathrm{m}} /{ }^{\circ} \mathrm{C} T_{\mathrm{pm}}$ & - & 66 & 68 & 68 & 68 & 70 & 70 \\
\hline$T_{\text {efm }}$ & - & 72 & 75 & 75 & 75 & 78 & 79 \\
\hline$\Delta H_{\mathrm{m}} / \mathrm{J} \mathrm{g}^{-1}$ & - & 26.4 & 58.9 & 71.0 & 91.6 & 115.5 & 153.0 \\
\hline$T_{\text {eic }}$ & - & 47 & 51 & 48 & 49 & 49 & 51 \\
\hline$T_{\mathrm{c}} /{ }^{\circ} \mathrm{C} \quad T_{\mathrm{pc}}$ & - & 43 & 43 & 44 & 45 & 45 & 45 \\
\hline$T_{\mathrm{efc}}$ & - & 36 & 35 & 36 & 38 & 34 & 35 \\
\hline$-\Delta H_{\mathrm{c}} / \mathrm{J} \mathrm{g}^{-1}$ & - & 23.1 & 52.8 & 64.0 & 81.6 & 104.4 & 136.4 \\
\hline$X_{c} / \%$ & - & 70 & 78 & 75 & 81 & 77 & 81 \\
\hline
\end{tabular}

DSC heating curve of PEO1 (Fig. 2(b)) also shows one endotherm, which represents the melting of the crystal phase of the semi-crystalline polymer. The melting point of neat PEO1 is $61{ }^{\circ} \mathrm{C}\left(T_{\text {eim }}\right), 72{ }^{\circ} \mathrm{C}$ $\left(T_{\mathrm{pm}}\right)$, and $79^{\circ} \mathrm{C}\left(T_{\text {efm }}\right)$ with corresponding melting enthalpy $\left(\Delta H_{\mathrm{m}}\right)$ of $159.6 \mathrm{~J} \mathrm{~g}^{-1}$. The DSC cooling curve of neat PEO1 (Fig. 2(c)) shows one exothermic peak, which corresponds to crystallization at temperature $51{ }^{\circ} \mathrm{C}\left(T_{\text {eic }}\right), 47{ }^{\circ} \mathrm{C}\left(T_{\mathrm{pc}}\right)$, and $35{ }^{\circ} \mathrm{C}$ $\left(T_{\text {efc }}\right)$ with corresponding enthalpy of crystallization $\left(\Delta H_{\mathrm{c}}\right)$ of $-145.8 \mathrm{~J} \mathrm{~g}^{-1}$. The neat PEO3 also shows one glass transition temperature that is identical to that of neat PEO1 (Tables 2 and 3). This fact proves that the increase in PEO molecular weight does not influence the glass transition temperature, which is in accordance with the conclusions made by Vrandečić et al. ${ }^{33}$ The temperatures of melting and crystallization of neat $\mathrm{PEO} 3$ are slightly different than those of neat PEO1, while corresponding enthalpies show lower values (Tables 2 and 3 ).

The degree of crystallinity of neat PEO1 and PEO3 calculated according to equation (1) is $85 \%$ and $81 \%$, respectively. The DSC heating curves of $\mathrm{PVC} / \mathrm{PEOs}$ blends show one glass transition temperature, which corresponds to the PEOs glass transition temperature and one endothermic peak, which corresponds to the melting of the PEOs crystal phase (Fig. 2(a) and (b)). The DSC cooling curves of PVC/PEOs blends show one exothermic peak, which represents crystallization of PEOs (Fig. 2(c)). The $T_{\mathrm{g}}$ of PVC in the PVC/PEOs blends could not be determined because it is overlapped with an endothermic peak of PEOs melting (Fig. 2(b)). As the PVC content increased in the investigated blends, the PEOs glass transition temperatures remains almost unchanged, while for samples with $80 \%$ of PVC content, the corresponding temperatures increased toward $T_{\mathrm{g}}$ of PVC by $3-5{ }^{\circ} \mathrm{C}$. The melting temperature of the PEOs in the blends depicted as $T_{\text {eim }}$ remained almost unchanged upon $\mathrm{PVC}$ addition, while values of $T_{\mathrm{pm}}$ and $T_{\text {efm }}$ decreased by $4-7{ }^{\circ} \mathrm{C}$ upon higher $\mathrm{PVC}^{\mathrm{pm}}$ addition (20\% for PEO1 and $80 \%$ for PEO3), as shown in Tables 2 and 3. Likewise, the crystallization temperatures of PEOs remained almost unchanged by increasing PVC content in the blends, and the difference between blends with $80 \%$ of PVC content and neat PEOs averaged $2-3{ }^{\circ} \mathrm{C}$. Upon PVC addition, the values of specific heat capacity $\left(\Delta c_{\mathrm{p}}\right)$, and corresponding enthalpies of melting $\left(\Delta H_{\mathrm{m}}\right)$, and crystallization $\left(\Delta H_{\mathrm{c}}\right)$ of the PEOs in the blends decreased (Tables 2 and 3), as can be seen from the area of endothermic and exothermic peak, respectively (Fig. 2). The degree of crystallinity $\left(X_{c}\right)$ of PEO1 upon $20 \%$ PVC addition in the blends increased by $5 \%$ (Table 2), while for PEO3 in the blends, it slightly changed until PVC content reached $80 \%$ when it decreased by $8 \%$ (Table 3). This is in the accordance with the work of Marenttete and Brown ${ }^{12}$ who investigated melting transitions of PEO in blends with PVC and concluded that, at best, PVC and PEO are only slightly miscible in the melt at elevated PVC content. The latter authors attributed the observed small melting temperature depressions to unspecified kinetic and morphological factors associated with the presence 
of isolated domains of non-crystallizable material in the melt, which is characteristic of immiscible blends. Hence, the existence of two separate glass transition temperatures in the polymer blends, or absence of a significant shift of PEOs glass transition temperature towards higher temperatures due to the presence of PVC, indicates the immiscibility of PVC and PEOs over most of the investigated composition range. The small depression of melting and crystallization temperatures at higher PVC content $(80 \%)$ indicates that PVC and PEOs are only slightly miscible in the melt. Likewise, the addition of PVC to PEO exerts a negligible effect on the degree of crystallinity of PEO, indicating that they are likely immiscible over most of the composition range. On the basis of the presented results of the DSC measurements, it can be concluded that the molecular weight of PEO has no major effect on miscibility with PVC in the melt.

\section{Dynamic mechanical analysis}

Since the glass transition temperature of PVC in the blend could not be determined from the DSC curve, due to overlapping with an endothermic effect of PEO melting, dynamic mechanical analysis (DMA) was employed. DMA is a technique that can provide information on the polymer-polymer interaction and interphase mixing. While DSC detects the change in heat capacity when a polymer shifts from glassy to rubbery state, DMA detects the change of the modulus. DMA is used to measure glass transition $\left(T_{\mathrm{g}}\right)$ and viscoelastic properties of polymeric amorphous materials. $T_{\mathrm{g}}$ is determined from the peak of the mechanical loss tangent $(\tan \delta)$ which is responsible for dissipation of energy during deformation, and is defined as: $\tan \delta=E " / E$, where $E^{\prime}$ is the elastic modulus and represents how much energy the polymer stores (storage modulus), and $E$ " is the viscous modulus and indicates the polymer's ability to dissipate energy as heat (loss modulus). ${ }^{34-35}$ The DMA curves for the storage modulus versus temperature $\left(E^{\prime} / T\right)$, and loss modulus versus temperature $(E " / T)$ of neat polymers and $\mathrm{PVC} /$ PEO1 blends are shown in Fig. 3, while the corresponding $T_{\mathrm{gs}}$ are summarized in Table 4 . The temperature at the point of inflection of the curve $E^{\prime} / T$ (Fig. 3(a)), which corresponds to a maximum of the curve tan $\delta / T$ and to a maximum of curve $E " / T$ (Fig. $3(b))$, is the glass transition temperature of the investigated neat polymers and PVC/PEOs blends. The glass transition temperature of neat PVC determined by DMA is $84{ }^{\circ} \mathrm{C}$, while $T$ from DSC measurement is $78{ }^{\circ} \mathrm{C}\left(T_{\text {eig }}\right)$. Likewise, $T_{\mathrm{g}}$ of neat PEO1 and PEO3 determined by DMA is $-43{ }^{\circ} \mathrm{C}$ and $-51{ }^{\circ} \mathrm{C}$, respectively, while from DSC measurement neat PEO1 also shows one $T_{\mathrm{g}}$ that is identical to that of neat PEO3 $\left(T_{\text {eig }}=-56^{\circ} \mathrm{C}\right)^{\mathrm{g}}$. This difference in ab-
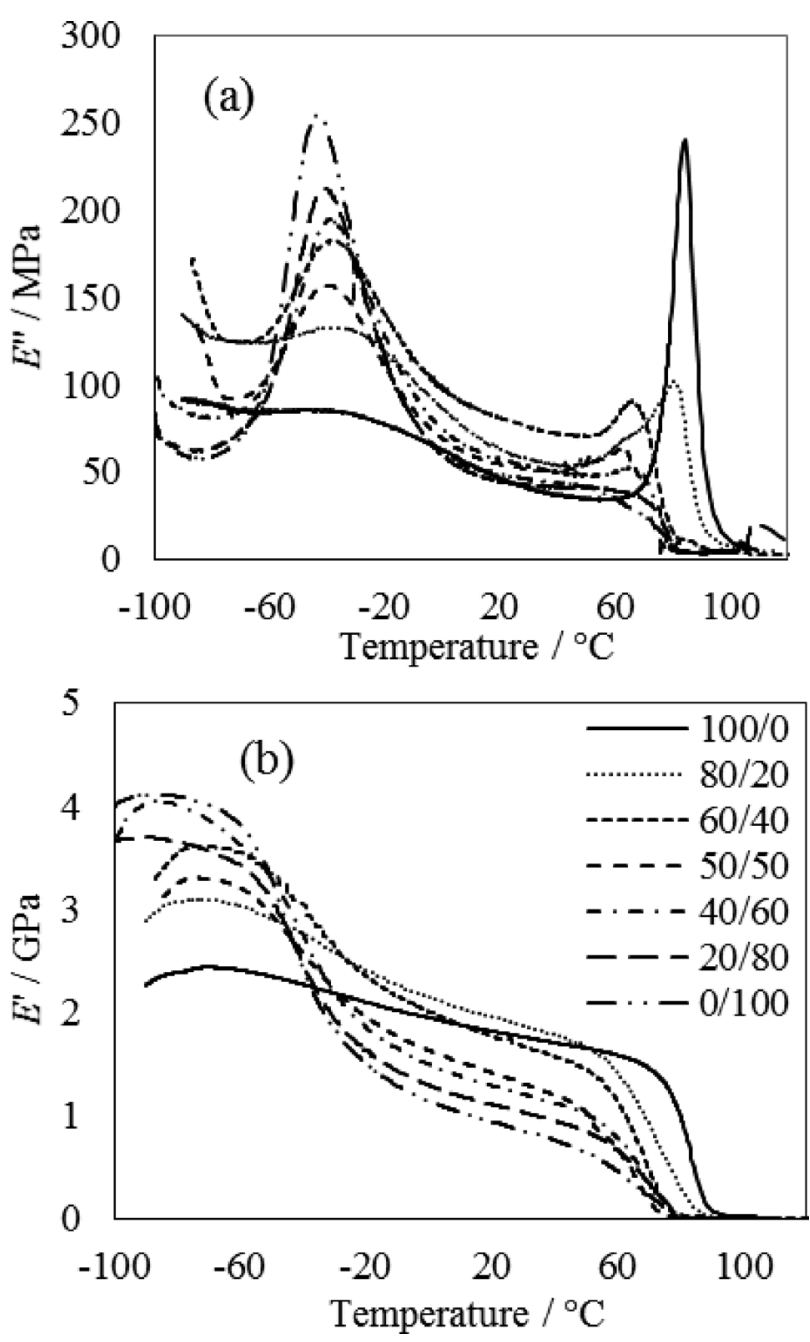

Fig. 3 - DMA curves of (a) loss modulus (E") versus temperature, and (b) storage modulus (E') versus temperature for PVC/PEO1 blends

Tab1e 4 - Glass transition temperatures $\left(T_{0}\right)$ of neat polymers and $P V C / P E O s$ blends determined by dynamic mechanical analysis, in ${ }^{\circ} \mathrm{C}$

\begin{tabular}{c|ccccc}
\hline \multirow{2}{*}{$\begin{array}{c}\text { Blend } \\
\text { composition }\end{array}$} & \multicolumn{2}{|c|}{ PVC/PEO1 } & \multicolumn{2}{c}{ PVC/PEO3 } \\
\cline { 2 - 5 } & $T_{\mathrm{g}}$ (PVC) & $T_{\mathrm{g}}$ (PEO1) & $T_{\mathrm{g}}$ (PVC) & $T_{\mathrm{g}}(\mathrm{PEO})$ \\
\hline $100 / 0$ & 84 & - & 84 & - \\
$80 / 20$ & 81 & -37 & 84 & -45 \\
$60 / 40$ & 66 & -38 & 66 & -47 \\
$50 / 50$ & 64 & -40 & 65 & -44 \\
$40 / 60$ & 67 & -39 & 66 & -47 \\
$20 / 80$ & 68 & -41 & 67 & -46 \\
$0 / 100$ & - & -43 & - & -51 \\
\hline
\end{tabular}

solute numbers determined by the DMA and DSC techniques originate from their sensitivity. Temperature transitions are determined more accurately by DMA than by DSC, as mechanical changes are more dramatic than changes in heat capacity. More- 


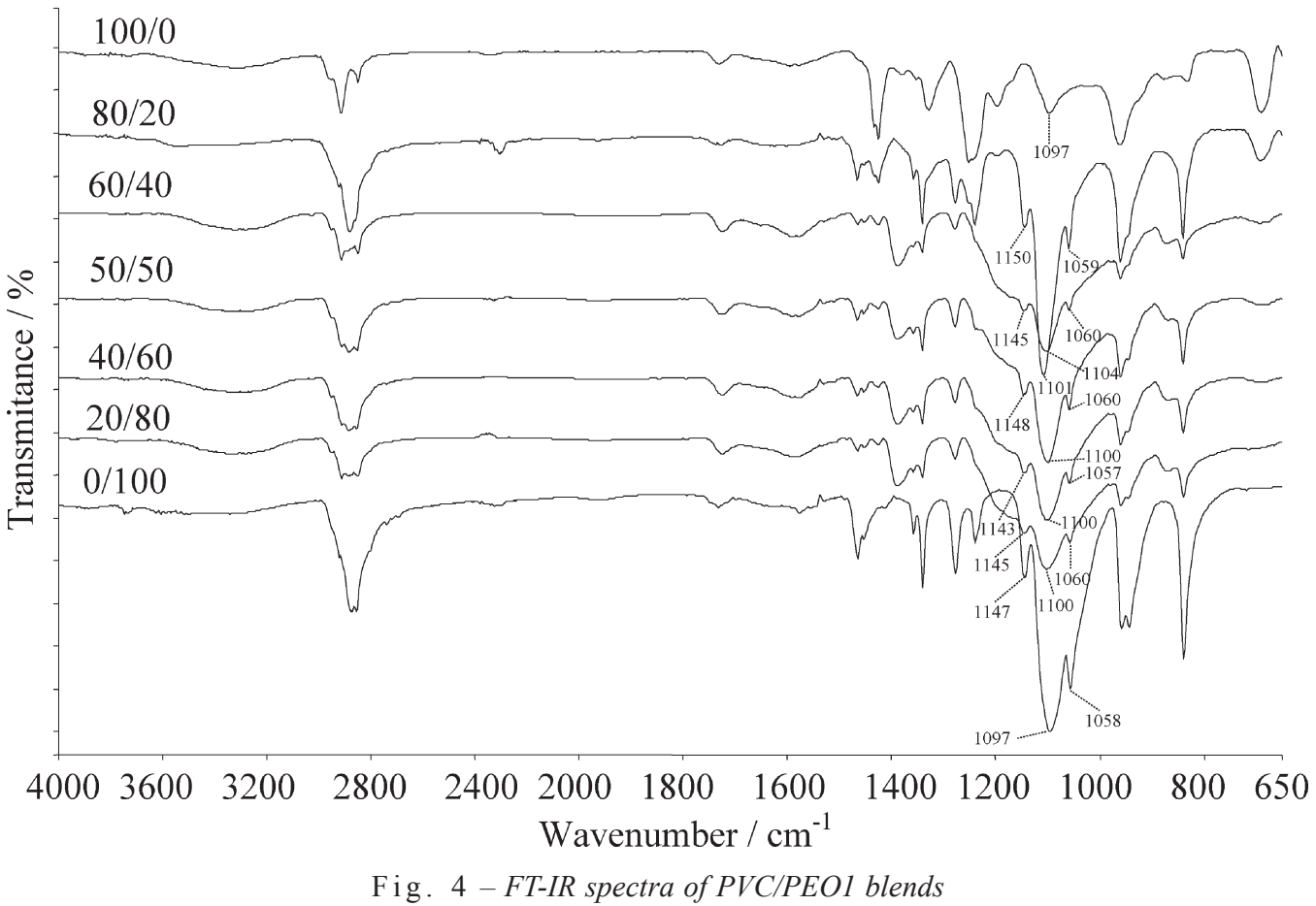

over, a frequency effect puts the mechanical $(1 \mathrm{~Hz})$ $T$ higher than that for a DSC measurement $(0.0001 \mathrm{~Hz}) .{ }^{35}$ Despite the differences, both methods show similar $T_{\mathrm{g}}$ evolution trend with PVC or PEOs content in the blend. The DMA curve of PVC/PEOs blends shows that both relaxations of PVC and PEOs persist, although they shift toward each other, which is characteristic of limited component miscibility (Fig. 3). As the PEOs content increased by $20 \mathrm{wt} \%(20 / 80)$ in the PVC/PEO1 blends, the PVC glass transition temperature decreased by $3{ }^{\circ} \mathrm{C}$, or remain unchanged in $\mathrm{PVC} /$ PEO3 blends (Table 4). By increasing PEOs content to $40 \mathrm{wt} \%(60 / 40)$, the $T$ of PVC significantly shifted from $84^{\circ} \mathrm{C}$ to $66^{\circ} \mathrm{C}$, and basically remained constant thereafter. On the other hand, $T$ of PEO1 shifted from $-43{ }^{\circ} \mathrm{C}$ to $-41{ }^{\circ} \mathrm{C}$, and $T^{\mathrm{g}}$ of PEO3 shifted from $-51{ }^{\circ} \mathrm{C}$ to $-46{ }^{\circ} \mathrm{C}$ for $20 \mathrm{wt} \%$ of PVC addition. As in the case of PVC, $T_{\mathrm{g}}$ of PEOs basically remained constant thereafter. It can be concluded, as well for DSC results, that the molecular weight of PEO has no major effect on the DMA spectra of PVC/PEOs blends, i.e. miscibility of PEOs with $\mathrm{PVC}$ in the melt. These results are in agreement with DSC results, and confirm that PVC and PEO are only slightly miscible in the melt at elevated PVC content. Margaritis and Kalfoglou ${ }^{9}$ came to a similar conclusion obtained by DMA, DSC, and optical microscopy. For the investigated PVC/PEO systems, the latter authors concluded that, in the temperature range of the PVC relaxation (where PEO melts), miscibility can be attained. At the other end of the composition range, the less amorphous PEO is available for mixing, but this does not nec- essarily mean that the increased amorphous phase would lead to miscibility. Finally, the authors stated that the interaction leading to limited miscibility could be attributed to the weak proton-accepting capacity of the PEO component and PVC providing the acidic $\alpha$-hydrogen

\section{Fourier transform infrared spectroscopy}

The FT-IR technique is important in blend studies since it allows description of the specific interactions between polymers, which may play an important role in polymer-polymer miscibility. The FT-IR spectra of neat polymers and PVC/PEO1 blends are presented in Fig. 4. The spectra of neat polymers contain absorption bands that are characteristic only for PVC or PEO, and these peaks can be used for the detection of the specific interactions between polymers in the blend, i.e. hydrogen bond. The neat PVC spectrum characteristic peaks are: ${ }^{19}$ $\mathrm{C}-\mathrm{Cl}$ stretching at 692,636 , and $615 \mathrm{~cm}^{-1}$, C-C stretching at $1099 \mathrm{~cm}^{-1}, \mathrm{C}-\mathrm{H}$ bending at 1243 and $1330 \mathrm{~cm}^{-1}(\mathrm{C}-\mathrm{H}$ in $\mathrm{CHCl})$, and $-\mathrm{CH}_{2}$ bending at $1426 \mathrm{~cm}^{-1}$. Characteristic absorption peaks of neat PEO have been identified as follows: ${ }^{36} \mathrm{CH}_{2}$ rocking and C-O-C scissor/deformation mode at $841 \mathrm{~cm}^{-1}$, asymmetrical and symmetrical $\mathrm{CH}_{2}$ rocking, $\mathrm{CH}_{2}$ stretching and C-C stretching at 960 and $945 \mathrm{~cm}^{-1}$, $\mathrm{C}-\mathrm{O}-\mathrm{O}$ symmetrical stretching at 1145, 1093 and $1060 \mathrm{~cm}^{-1}$ (triplet), asymmetrical and symmetrical $\mathrm{CH}_{2}$ twisting at 1279 and $1241 \mathrm{~cm}^{-1}, \mathrm{CH}_{2}$ wagging at 1360 and $1341 \mathrm{~cm}^{-1}$ (doublet) and asymmetrical and symmetrical $\mathrm{CH}_{2}$ scissoring at 1466 and $1456 \mathrm{~cm}^{-1}$. There is no difference in FT-IR spectra of neat 
PEOs due to their different molecular weight. Some important characteristic absorption peaks of neat polymers and PVC/PEOs blends are summarized in Table 5. In the spectral range of $1000-1300 \mathrm{~cm}^{-1}$, the crystalline phase of PEO is featured by the characteristic triplet with the sharp central peak of strong intensity. Changes in the intensity, shape, and position of the characteristic triplet can be associated with the interaction between PEO and PVC. The triplet maintains its shape, while at the initial addition of PVC $(20 \%)$, the position of the maximum peak is shifted from 1096 (PEO1) and 1097 (PEO3) $\mathrm{cm}^{-1}$ to 1100 and $1102 \mathrm{~cm}^{-1}$, respectively. Moreover, no further shifting of the maximum peak is observed as the PVC content in the PVC/PEOs blends increases to $80 \%$ when it shifted to 1101 (PEO1) and 1108 (PEO3) $\mathrm{cm}^{-1}$. However, we believe that this upshifting is not significant enough to be attributed to hydrogen bonding between $\alpha$-hydrogen atoms of PVC and the oxygen atoms of PEO. Besides, no reduction in both intensity and position of the two shoulders at 1145 and $1060 \mathrm{~cm}^{-1}$ is noted, implying that PEO crystallinity remains unchanged with increasing content of the amorphous PVC. Likewise, other bands corresponding to the neat polymers and PVC/PEOs blends depicted in Table 5 remain almost the same in band frequency, indicating that there are no dipole-dipole interactions occurring in the PVC/PEO blends. These results are in agreement with DSC and DMA results, and confirm that the addition of amorphous PVC in the PVC/ PEOs blends does not influence the crystallization of PEO to a greater extent.

\section{Scanning electron microscopy}

The miscibility of a polymer blend may be evaluated by the analysis of the surface morphology. SEM photographs of neat polymers and selected $\mathrm{PVC} / \mathrm{PEO} 1$ blends films are shown in Fig. 5. The scanning electron micrograph for the extruded neat PVC sample (Fig. 5 (a)) reveals a rough surface with no noticeable crystalline structure, which is the morphological feature expected of an amorphous polymer. ${ }^{37}$ The morphology of the extruded neat PEO1 sample is featured in Fig. 5(d). Neat PEO1 shows a birefringence pattern and uniform distribution of large crystals embedded in a semi-crystalline matrix typical of PEO samples. ${ }^{38-39}$ In a blend of amorphous (PVC) with semi-crystalline polymer (PEOs), dispersion may be observed by SEM. ${ }^{40}$ Based on the DSC, DMA, and FTIR results, we concluded that PVC and PEO are only slightly miscible in the melt at elevated PVC content. SEM photographs of PVC/PEO1 blends with 20 and $50 \%$ of PEO1 are shown in Fig. 5(b) and (c). The morphology of investigated 80/20 blend reveals dark areas, which represent large and irregularly shaped crystalline domains of PEO1 surrounded by PVC amorphous phase (brighter area) (Fig. 5(b)). When

Table 5 - Wave numbers of characteristic absorption peaks of neat polymers and PVC/PEOs blends, in $\mathrm{cm}^{-1}$

\begin{tabular}{|c|c|c|c|c|c|c|c|c|}
\hline $\begin{array}{c}\text { Blend } \\
\text { composition }\end{array}$ & $\begin{array}{c}\mathrm{CH}_{2} \\
\text { scissoring } \\
\text { asy./sym. }\end{array}$ & $\begin{array}{c}\mathrm{CH}_{2} \\
\text { bending }\end{array}$ & $\begin{array}{c}\mathrm{CH}_{2} \\
\text { wagging } \\
\text { (doublet) }\end{array}$ & $\begin{array}{c}\mathrm{CH}_{2} \\
\text { twisting } \\
\text { asy./sym. }\end{array}$ & $\begin{array}{c}\text { C-O-C } \\
\text { stretching } \\
\text { sym. (triplet) }\end{array}$ & $\begin{array}{l}\mathrm{CH}_{2} / \mathrm{C}-\mathrm{C} \\
\text { asy./sym. } \\
\text { rocking } \\
\text { /stretching }\end{array}$ & $\mid \begin{array}{c}\mathrm{CH}_{2} / \mathrm{C}-\mathrm{O}-\mathrm{C} \\
\text { rocking } \\
\text { scissor }\end{array}$ & $\begin{array}{c}\mathrm{C}-\mathrm{Cl} \\
\text { stretching }\end{array}$ \\
\hline \multicolumn{9}{|c|}{$\mathrm{PVC} / \mathrm{PEO} 1$} \\
\hline $100 / 0$ & - & 1426 & 1330 & 1252 & 1097 & 961 & 832 & 696 \\
\hline $80 / 20$ & 1467 & 1426 & 1358,1343 & 1243 & $1150,1101,1059$ & 962 & 842 & 694 \\
\hline $60 / 40$ & 1454 & 1427 & 1358,1348 & 1282 & $1145,1104,1060$ & 963 & 842 & 962 \\
\hline $50 / 50$ & 1467 & 1426 & 1358,1342 & 1279 & $1148,1100,1060$ & 962 & 841 & 691 \\
\hline $40 / 60$ & 1467 & 1426 & 1358,1342 & 1279 & $1143,1100,1057$ & 962 & 841 & 679 \\
\hline $20 / 80$ & - & 1426 & 1358,1343 & 1279 & $1145,1100,1060$ & 961 & 840 & \\
\hline $0 / 100$ & 1466 & - & 1358,1341 & 1278 & $1147,1097,1058$ & 960,946 & 840 & \\
\hline \multicolumn{9}{|c|}{$\mathrm{PVC} / \mathrm{PEO} 3$} \\
\hline $80 / 20$ & 1466 & 1427 & 1360,1343 & 1280 & $1148,1108,1062$ & 963 & 842 & 683,689 \\
\hline $60 / 40$ & 1466 & 1427 & 1358,1342 & 1279 & $1147,1103,1060$ & 962 & 842 & 683,689 \\
\hline $50 / 50$ & 1466 & 1427 & 1358,1342 & 1279 & $1146,1103,1060$ & 962 & 841 & 683,695 \\
\hline $40 / 60$ & 1467 & 1427 & 1360,1342 & 1279 & $1146,1102,1060$ & 961 & 841 & 684,695 \\
\hline $20 / 80$ & 1466 & 1427 & 1360,1342 & 1280 & $1148,1102,1060$ & 961 & 840 & 682 \\
\hline $0 / 100$ & 1467 & - & 1360,1342 & 1279 & $1146,1096,1057$ & 960 & 840 & \\
\hline
\end{tabular}



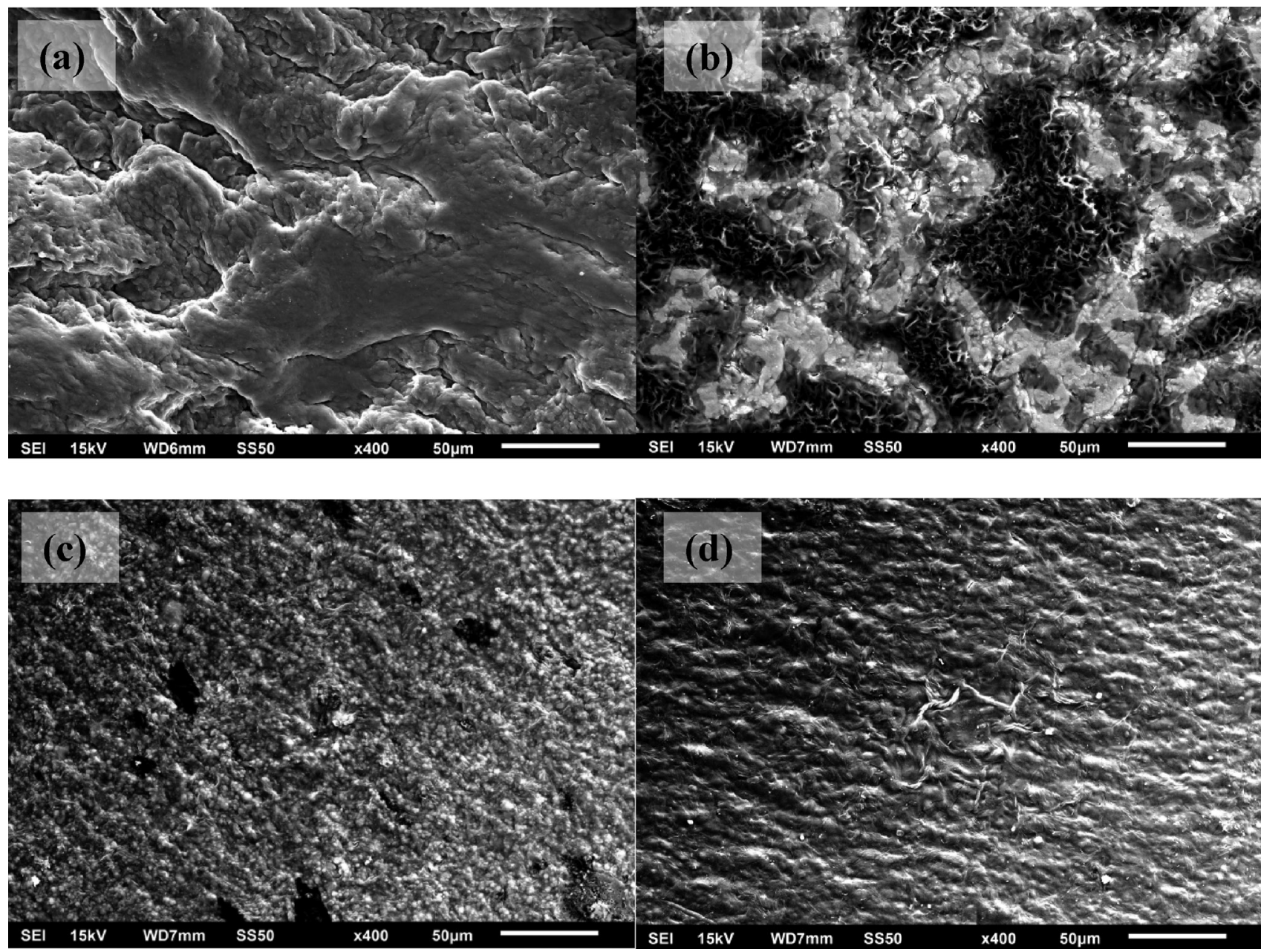

Fig. 5 - SEM micrographs of (a) neat PVC, (b) 80/20 PVC/PEO1 blend, (c) 50/50 PVC/PEO1 blend and (d) neat PEO1

a semi-crystalline polymer like PEO crystallizes in the presence of a non-crystallisable component like amorphous PVC, one can expect that the accumulation of the amorphous component occurs outside the crystalline regions. This will cause a depression in the melting point; hence, miscibility could be expected. ${ }^{4}$ However, only a slight decrease is observed for investigated 80/20 PVC/PEO1 blend (Table 2). Two phases exist separately, but each may contain some dissolved portion of the other. Hence, as the amount of PEO1 is increased in the blend there is a denser distribution of PEO1 at darker areas (Fig. 5 (b)) in comparison to brighter areas with low concentration of PEO1 in the PVC matrix. Therefore, in a blend of PVC with PEOs, only a weak interaction may be observed in the melt at elevated PVC content as confirmed by DSC, DMA and FTIR. Although, the PEO crystalline morphology is very much dependent on the molecular weight and polydispersity, ${ }^{41}$ the molecular weight of $\mathrm{PEO}$, as concluded above by DSC, DMA and FTIR analysis, has no major effect on the morphological features of PVC/PEOs blends.

\section{Conclusion}

In order to evaluate interactions of amorphous PVC and semi-crystalline PEO of different molecular weights in solution and solid state, viscosimetric, DSC, DMA, FT-IR, and SEM experiments were performed. To evaluate interactions in the polymer blend from viscosimetric data, according to the Sun theory, the parameter $\alpha$ has been used. Positive values of $\alpha$ were found for all investigated PVC/PEOs blends and they were about ten times smaller for PVC blends with PEO of higher molecular weight, indicating that, when low molecular weight PEO1 is used, miscibility in solution could be expected. The existence of two separate glass transition temperatures in the polymer blends, or absence of significant shift of PEOs glass transition temperature due to the presence of PVC, indicates the immiscibility of PVC and PEOs over most of the investigated composition range. The small depression of melting and crystallization temperatures at higher PVC content $(80 \%)$ indicates that PVC and PEOs are only slightly miscible in the melt. Likewise, the addition of PVC to PEO exerts a negligible effect on the degree of crys- 
tallinity of PEO, indicating that they are likely immiscible over most of the composition range. The results of DMA analysis are in agreement with DSC results and confirm that $\mathrm{PVC}$ and $\mathrm{PEO}$ are only slightly miscible at elevated PVC content. The observed shiftings of peak maxima in FT-IR spectra are not significant enough to confirm the interactions between the investigated polymers in solid state, as well as the results of SEM analysis. The influence of molecular weight of PEO on miscibility could be observed only in a solution where the crystalline structure of PEO had been destroyed and both polymers were able to exist in a molecularly dispersed state.

\section{References}

1. Hassouna, F., Morlat-Thérias, S., Mailhot, G., Gardette, J. $L$., Influence of water on the photodegradation of poly(ethylene oxide), Polym. Degrad. Stab. 92 (2007) 2042. doi: http://dx.doi.org/10.1016/j.polymdegradstab.2007.07.016

2. Ramesh, S., Yahaya, A. H., Arof, A. K., Miscibility studies of PVC blends (PVC/PMMA and PVC/PEO) based polymer electrolytes, Solid State Ionics 148 (2002) 483. doi: http://dx.doi.org/10.1016/S0167-2738(02)00091-7

3. Messori, M., Toselli, M., Pilati, F., Fabbri, E., Fabbri, P., Pasquali, L., Nannarone, S., Prevention of plasticizer leaching from PVC medical devices by using organic-inorganic hybrid coatings, Polymer 45 (2004) 805. doi: http://dx.doi.org/10.1016/j.polymer.2003.12.006

4. Neiro, M. S., Dragunski, D. C., Rubira, A. F., Muniz, E. C., Miscibility of PVC/PEO blends by viscosimetric, microscopic and thermal analyses, Eur. Polym. J. 36 (2000) 583. doi: http://dx.doi.org/10.1016/S0014-3057(99)00082-8

5. Reddeppa, N., Sharma, A. K., Narasimha Rao, V. V. R., Chen, $W$., Preparation and characterization of pure and $\mathrm{KBr}$ doped polymer blend (PVC/PEO) electrolyte thin films, Microelectronic Engineering 112 (2013) 57. doi: http://dx.doi.org/10.1016/j.mee.2013.05.015

6. Reddeppa, N., Sharma, A. K., Narasimha Rao, V. V. R., Chen, $W$., AC conduction mechanism and battery discharge characteristics of (PVC/PEO) polyblend films complexed with potassium chloride, Measurement 47 (2014) 33. doi: http://dx.doi.org/10.1016/j.measurement.2013.08.047

7. Luo, Z., Jiang, J., Molecular dynamics and dissipative particle dynamics simulations for the miscibility of poly(ethylene oxide)/poly(vinyl chloride) blends, Polymer 51 (2010) 291. doi: http://dx.doi.org/10.1016/j.polymer.2009.11.024

8. Ramesh, S., Winie, T., Arof, A. K., Investigation of mechanical properties of polyvinyl chloride-polyethylene oxide (PVC-PEO) based polymer electrolytes for lithium polymer cells, Eur. Polym. J. 43 (2007) 1963. doi: http://dx.doi.org/10.1016/j.eurpolymj.2007.02.006

9. Katime, I. A., Anasagasti, M. S., Peleteiro, M. C., Valenciano, $R$., Compatibility of poly(ethylene oxide)/poly(vinyl chloride) blends by differential scanning calorimetry, Eur Polym. J. 23 (1987) 907. doi: http://dx.doi.org/10.1016/0014-3057(87)90067-X

10. Margaritis, A. G., Kalfoglou, N. K., Compatibility of Poly( vinyl chloride) with Polyalkyleneoxides. I. Poly( methylene oxide) and Poly( ethylene oxide), Polym. Sci. B. 26 (1988) 1595.

doi: http://dx.doi.org/10.1002/polb.1988.090260804
11. Marco, C., Gomez, M. A., Fatou, J. G., Etxeberria, A., Elorza, M. M., Iruin, J. J., Miscibility of poly(vinyl chloride)/poly(ethylene oxide) blends-I Thermal properties and solid state ${ }^{13} \mathrm{C}$-NMR study, Eur. Polym. J. 29 (1993) 1477. doi: http://dx.doi.org/10.1016/0014-3057(93)90062-K

12. Etxeberria, A., Elorza, J. M., Iruin, J. J., Marco, C., Gomez, M. A., Fatou, J. G., Miscibility of poly(vinyl chloride)/poly(ethylene oxide) blends-II. An inverse gas chromatography study, Eur. Polym. J. 29 (1993) 1483. doi: http://dx.doi.org/10.1016/0014-3057(93)90063-L

13. Marentette, J. M., Brown, G. R., The crystallization of poly(ethylene oxide) in blends with neat and plasticized poly(vinyl chloride), Polymer 39 (1998) 1415. doi: http://dx.doi.org/10.1016/S0032-3861(97)00154-7

14. Pielichowski, K., Thermal energy storage systems based on poly(vinyl chloride) blends, Eur. Polym. J. 35 (1999) 27. doi: http://dx.doi.org/10.1016/S0014-3057(98)00107-4

15. Al-Ramadin, Y., Optical properties of poly(vinyl chloride)/ poly(ethylene oxide) blend, Opt. Mater. 14 (2000) 287. doi: http://dx.doi.org/10.1016/S0925-3467(00)00007-0

16. Guo, L., Shi, G., Liang, Y., Poly(ethylene glycol)s catalyzed homogeneous dehydrochlorination of poly(vinyl chloride) with potassium hydroxide, Polymer 42 (2001) 5581. doi: http://dx.doi.org/10.1016/S0032-3861(01)00037-4

17. Huang, X. D., Goh, S. H., Miscibility of C 60 -end-capped poly(ethylene oxide) with poly(vinyl chloride), Polymer $\mathbf{4 3}$ (2002) 1417. doi: http://dx.doi.org/10.1016/S0032-3861(01)00705-4

18. Castro, R. E. N., Toledo, E. A., Rubira, A. F., Muniz, E. C., Crystallisation and miscibility of poly(ethylene oxide)/ poly(vinyl chloride) blends, J. Mat. Sci. 38 (2003) 699. doi: http://dx.doi.org/10.1023/A:1021888310159

19. Kaczmarek, H., Kowalonek, J., Klusek, Z., Pierzgalski, S., Datta, S., Studies of photooxidative degradation of poly(vinyl chloride)/poly(ethylene oxide) blends, J. Polym. Sci. B 42 (2004) 585. doi: http://dx.doi.org/10.1002/polb.10690

20. Balakrishnan, B., Jayakrishnan, A., Chemical modification of poly(vinyl chloride) using poly(ethylene glycol) to improve blood compatibility, Trends Biomater. Art. Org. 18 (2005) 230. doi: http://dx.doi.org/10.1016/j.biomaterials.2004.09.032

21. Ramesh, S., Arof, A. K., The evaluation of miscibility of poly(vinyl chloride) and poly(ethylene oxide) blends by DSC, refractive index and XRD analyses, Int. Polym. Process. 4 (2009) 354. doi: http://dx.doi.org/10.3139/217.2275

22. Wu, Y.-H., Zhou, Q., Zhao, T., Deng, M.-L., Zhang, J., Wang, Y.-Z., Poly(ethylene glycol) enhanced dehydrochlorination of poly(vinyl chloride), J. Haz. Mat. 163 (2009) 1408. doi: http://dx.doi.org/10.1016/j.jhazmat.2008.07.047

23. Rajendran, S., Babu, R. S., Rani, M. U., Effect of complexing salt on conductivity of PVC/PEO polymer blend electrolytes, Bull. Mater. Sci. 34 (2011) 1525. doi: http://dx.doi.org/10.1007/s12034-011-0354-3

24. Jakić, M., Vrandečić, N. S., Klarić, I., Thermal degradation of poly(vinyl chloride)/ poly(ethylene oxide) blends: Thermogravimetric analysis, Polym. Degrad. Stab. 98 (2013) 1738. doi: http://dx.doi.org/10.1016/j.polymdegradstab.2013.05.024

25. ISO 11357-2: 2009 Plastics-Differential scanning calorimetry (DSC)-Part 2: Determination of glass transition temperature. 
26. ISO 11357-3: 2009 Plastics - Differential scanning calorimetry (DSC) - Part 3: Determination of temperature and enthalpy of melting and crystallization.

27. Rocco, A. M., Pereira, R. P., Felisberti, M. I., Miscibility, crystallinity and morphological behavior of binary blends of poly(ethylene oxide) and poly(methyl vinyl ether-maleic acid), Polymer 42 (2001) 5199. doi: http://dx.doi.org/10.1016/S0032-3861(00)00784-9

28. Sun, Z., Wang, W., Feng, Z., Criterion of polymer-polymer miscibility determined by viscometry, Eur. Polym. J. 28 (1992) 1259. doi: http://dx.doi.org/10.1016/0014-3057(92)90215-N

29. Jiang, W. H., Han, S. J., An improved criterion of polymerpolymer miscibility determined by viscometry, Eur. Polym. J. 34 (1998) 1579. doi: http://dx.doi.org/10.1016/S0014-3057(98)00022-6

30. Hong, P. D., Huang, H. T., Chou, C. M., Study of the solvent effect on miscibility between poly(vinyl chloride) and poly(methyl methacrylate) in the solution state - viscometric measurements, Polym. Int. 49 (2000) 407.

doi: http://dx.doi.org/10.1002/(SICI)1097-0126(200004)49: 4<407::AID-PI394>3.0.CO;2-K

31. Pan, Y., Cheng, R. C., Xue, F., Fu, W., A new viscometric criterion for polymer-polymer interaction, Eur. Polym. J. 38 (2002) 1703. doi: http://dx.doi.org/10.1016/S0014-3057(02)00027-7

32. Aroguz, A. Z., Baysal, B. M., Miscibility studies on blends of poly(phenylene oxide)/brominated polystyrene by viscometry, Eur. Polym. J. 42 (2006) 311. doi: http://dx.doi.org/10.1016/j.eurpolymj.2005.07.012

33. Vrandečić, N. S., Erceg, M., Jakić, M., Klarić, I., Kinetic analysis of thermal degradation of poly(ethylene glycol) and poly(ethylene oxide)s of different molecular weight, Thermochim. Acta 498 (2010) 71. doi: http://dx.doi.org/10.1016/j.tca.2009.10.005
34. Abiad, M. G., Campanella, O. H., Carvajal, M. T., Assessment of thermal transitions by dynamic mechanical analysis (DMA) using a novel disposable powder holder, Pharmaceutics 2 (2010) 78 . doi: http://dx.doi.org/10.3390/pharmaceutics2020078

35. Yang, M., Wang, P., Suwardie, H., Gogos, C., Determination of acetaminophen's solubility in poly(ethylene oxide) by rheological, thermal and microscopic methods, Int. J. Pharm. 403 (2011) 83. doi: http://dx.doi.org/10.1016/j.ijpharm.2010.10.026

36. Sim, L. H., Gan, S. N., Chan, C. H., Yahya R., ATR-FTIR studies on ion interaction of lithium perchlorate in polyacrylate/poly(ethylene oxide) blends, Spectrochim. Acta Part A 76 (2010) 287. doi: http://dx.doi.org/10.1016/j.saa.2009.09.031

37. Xie, X.-L., Liu, Q.-X., Li, R. K.-Y., Zhou, X.-P., Zhang, Q. $X$., Yu, Z.-Z., Mai, Y.-W., Rheological and mechanical properties of $\mathrm{PVC} / \mathrm{CaCO}_{3}$ nanocomposites prepared by in situ polymerization, Polymer 45 (2004) 6665 doi: http://dx.doi.org/10.1016/j.polymer.2004.07.045

38. Rocco, A. M., Moreira, D. P., Pereira, R. P., Specific interactions in blends of poly(ethylene oxide) and poly(bisphenol A-co-epichlorohydrin): FTIR and thermal study, Eur. Polym. J. 39 (2003) 1925 doi: http://dx.doi.org/10.1016/S0014-3057(03)00098-3

39. Jagadish, R. S., Raj, B., Properties and sorption studies of polyethylene oxide-starch blended films, Food Hydrocolloids 25 (2011) 1572. doi: http://dx.doi.org/10.1016/j.foodhyd.2011.01.009

40. Corradini, E., Rubira, A. F., Muniz, E. C., Miscibility of PVC/EVA hydrolysed blends by viscosimetric, microscopic and thermal analysis, Eur. Polym. J. 33 (1997) 1651. doi: http://dx.doi.org/10.1016/S0014-3057(97)00047-5

41. Fukatsu, K., Kokot, S., Degradation of poly(ethylene oxide) by electro-generated active species in aqueous halide medium, Polym. Degrad. Stab. 72 (2001) 353. doi: http://dx.doi.org/10.1016/S0141-3910(01)00037-4 